\title{
PENGARUH PELATIHAN DAN PENGALAMAN KERJA TERHADAP PROFESIONALISME
}

\author{
Sarfika ${ }^{1) *}$, Mappamiring ${ }^{2)}$, Aswar ${ }^{3)}$ \\ 1) Program studi Manajemen, Stiem Bongaya Makassar \\ Penulis Korespondensi: Sarfika12@gmail.com
}

\begin{abstract}
Abstrak
Penelitian ini bertujuan untuk menguji perngaruh pelatihan kerja terhadap profesionalisme pegawai dimoderasi pengalaman kerja pada BKKBN Makassar. Populasi dalam penelitian ini adalah seluruh pegawai yang bekerja pada BKKBN Makassar. Sebanyak 106 pegawai, sampel dalam penelitian ini sebanyak 51 responden. Hasil penelitian menunjukkan bahwa pelatihan kerja memiliki pengaruh terhdap profesioanalisme pegawai dan pengalaman kerja memoderasi pengaruh pelatihan kerja terhadap profesionalisme pegawai.
\end{abstract}

Keywords: Pengalaman, Profesionalisme, Pelatihan 


\section{PENDAHULUAN}

Program kependudukan dan keluarga berencana sangat penting bagi pembangunan bangsa, termasuk dimakassar, BKKBN Perwakilan Sulawesi Selatan yang berkantor di jalan A.P Pettrani No. 122 Makassar, merupakan lembaga pemerintah yang mempunyai tugas melaksanakan tugas pemrintahan dibidang pengendalian penduduk dan penyelenggaraan keluarga berencana. BKKBN memiliki program-program yang bertujuan dapat melahirka generasi muda dengan jiwa kepmiminan kolaboratif , mampu beradaptasi dengan kemajuan teknologi, sekaligus meimilki wawasan kepndudukan, keluarga berencana dan pembangunan keluarga. Menurut Hasibuan $(2007 ; 2010)$ mengemukakan bahwa manajemen sumber daya manusia adalah "ilmu dan seni mengatur hubungan dan peranan tenaga kerja agar Eektif dan efesien membantu terwujudnya tujuan perusahaan, karyawan dan masyarakat". Sebagai salah satu Badan Usaha Milik Negara, BKKBN Memiliki tugas sebagai Badan usaha dibidang pengendalian penduduk dan keluarga berencana, maka BKKBN. Sehingga. Profesionalisme merupakan paham atau keyakinan bahwa sikap dan tindakan aparatur dalam menyelenggarakan kegiatan pemerintahan dan pelayanan selalu didasarkan pada ilmu pengetahuan dan nilai-nilai profesi paratur yang mengutamakan kepentingn publik (Dwiyanto, 2011:157. Bukti penelitian terdahulu memberikan bukti bahwa pelatihan kerja berpengaruh signifikan terhadap profesionalisme Septi Indrayani., (2019) ; Muhammad rakib dkk., (2016) ; Daniel dkk., (2019) ; Joni Roza., (2016) ; hasil penelitian tersebut memperoleh bantahan dari peneliti lainya, bahwa pelatihan tidak memiliki pengaruh secara sinifikan terhadap profesionalisme eliyanto., dkk (2013) Selain pelatihan kerja, pengalaman kerja juga dapat mendukung profesionalisme pegawai.

Hasil observasi peneliti temukan dimana beberapa staff dalam melayani kurang professional, seperti meninggalkan pelanggan, memainkan Gadget HP pada jam kerja, ada bebeapa staff yang peneliti perhatikan tidak duduk sesuai dengan ruang kerja mereka , sehingga terkesan tidak hal yang bisa dikerjakan.

Sehingga dengan demikian peneliti tertarik untuk meneliti lebih lanjut Pengaruh
Pelatihan Dan Pengalaman Kerja Terhadap Profesionalisme.

\section{TINJAUAN PUSTAKA}

Pelatihan (Trainning) Merupakan proses pembelajaran yang melibatkan perolehan keahlian, konsep, peraturan atau sikap untuk meningkatan kinerja kerja (Simamora 2010:273). Siagian (2004) berpendapat bahwa pelaksanaan pelatihan kerja dimaksudkan untuk mendapatkan tenaga kerja yang memiliki pengetahuan ,keterampilan yang baik, kemampuan dan sikap yang baik untuk mengisi jabatan pekerjaan yang tersedia dengan produktivitas kerja yng tinggi, yang mampu menghasilkan hasil kerja yang baik. Kebutuhan untuk setiap pekerja sangat beragam, untuk itu pelatihan kerja perlu dipersiapakan dan dilaksanakan sesuai dengan bidang pekerjaannya, dengan demikian pekerjaan yang dihadapi akan dapat dikerjakan dengan lancar sesuai dengan prosedur yang benar.

Pengalaman kerja adalah keseluruhan pelajaran yang dipetik oleh seseorang dari peristiwa - peristiwa dilalui dalam perjalanan hidupnya ( siagian, 2008:60) . Foste r(2001: 43) mengemukakan bahwa untuk menentukan berpengalaman tidaknya seorang karyawan yang sekaligus dapat digunakan sebagai indicator pengalaman kerja yaitu (1) Lama waktu / masa kerja, yang telah ditempuh seseorang sehingga dapat memahami tugastugas suatu pekerjaan dan telah melaksankan dengan baik ; (2) tingkat pengetahuan dan keterampilan,pengetahuan merujuk pada konsep, prinsip, prosedur, kebijakan atau informasi lain yang dibutuhkan oleh pegawai, sedangkan keterampilan merujuk untuk mencapai atau menjalankan tugas atau pekerjaan ; (3) Penguasaan terhadap pekerjaan dan peralatan, tingkat penguasaan seseorang dalam pelaksanaan aspek-aspek teknik peraltan dan teknik pekerjaan.

$$
\text { Joko Affandi (2002: }
$$

mengemukakan bahwa paling tidak ada empat ciri yang bisa diidentifikasi sebagai indicator untuk melihat tingkat profesionalisme seseorang.Pertama, Penguasaan ilmu pengetahuan seseorang di bidang tertentu, dan ketekuknannya mengukuiti pernkembangan ilmu yang dikuasai.kedua, Kemampuan seseorang dalam menerpakan ilmu yang dikuasai, khusunya yang berguna bagi 
kepentingan bersama.Ketiga, Ketaatan dalam melaksankan dan menjunjung tinggi etika keilmuan, serta kemampuan untuk memahami dan menghormati nilai-nilai sosial yang berlalku di lingkungannya.dan terakhir adalah Rasa tanggung jawab terhadap Tuhan, bangsa, dan negara, masyarakat, keluarga, serta diri sendiri atas tindak tanduk dan perilaku dalam mengemban tugas berkaitan dengan penguasaan dan penerapan bidang ilmu yang dimiliki.

\section{METODE PENELITIAN}

Penelitian ini termasuk penjelasan (explanatory research) yang bertujuan untuk menguji hubungan antara variabel atau bagaimana suatu variabel mempengaruhi variabel lainnya. Penelitian ini juga termasuk penedekatan penelitian kuantitatif, disebut kuantitatif karena banyak menggunkan angkat, mulai dari pengumpulan data, penafsiran terhadap data serta penampilan dan hasilnya, demikian juga dengan pemahaman akan kesimpulan penelitian. Subjek penelitian ini yaitu kantor BKKBN provinsi sulawesi selatan dan objecknya adalah pegawai kantor BKKBN. Teknik pengumpulan data dalam penelitian ini yaitu: observasi dan kuesioner. Pengukuran variabeldalam penelitian ini yang diukur menggunakan Skala Ordinal dengan menggunakan Skala Likert, skor 1 untuk jawaban sangat rendah (SR), skor 2 untuk jawaban rendah (R), skor 3 untuk jawaban netral $(\mathrm{N})$, skor 4 untuk jawaban tinggi $(\mathrm{T})$, dan untuk skor 5 untuk jawaban sangat tinggi (ST)

Responden dalam penelitian ini adalah para pegawai pada Kantor BKKBN Provinsi SulSel yang berpartisipasi dalam penelitian ini selanjutnya dapat diperinci berdasarkan jenis kelamin, usia, pendidikan terakhir dan masa kerja.

Metode analisis data ini yaitu uji statistk deskriptif variabel, uji instrumen, uji asumsi klasik, uji regresi berganda, uji regresi moderasi, uji kelayakan model (uji F), dan uji koefisie regresi parsial (uji T), pengujian ini dilakukan melalui spss versi 22

Berdasarkan metode analisis tersebut, hipotesis (Ha) yang akan diuji yaitu :
H1 : Pelatihan berpengaruh positif signifikan terhadap Profesionalisme

H2 : Pengalaman Kerja Memoderasi pengaruh pelatihan terhadap profesionalisme

\section{HASIL DAN PEMBAHASAN}

Pengujian pertama dilakukan yang dilakukan yaitu uji instrumen, dengan uji validitas. Hasil pengujian sebagai berikut:

Tabel 1. Uji validitas

\begin{tabular}{|l|l|l|l|l|}
\hline indikator & Corellaction & $\begin{array}{l}r \\
\text { tabel } \\
5 \%\end{array}$ & $\begin{array}{l}\text { Sig. } \\
(2- \\
\text { tailed })\end{array}$ & Keterangan \\
\hline X11 & $\mathbf{0 . 7 4 3}$ & $\mathbf{0 . 2 7 5}$ & $\mathbf{0 . 0 0 0}$ & Valid \\
\hline X12 & $\mathbf{0 . 8 2 0}$ & $\mathbf{0 . 2 7 5}$ & $\mathbf{0 . 0 0 0}$ & valid \\
\hline X13 & $\mathbf{0 . 7 3 5}$ & $\mathbf{0 . 2 7 5}$ & $\mathbf{0 . 0 0 0}$ & Valid \\
\hline X14 & $\mathbf{0 . 5 4 2}$ & $\mathbf{0 . 2 7 5}$ & $\mathbf{0 . 0 0 0}$ & Valid \\
\hline X21 & $\mathbf{0 . 4 3 0}$ & $\mathbf{0 . 2 7 5}$ & $\mathbf{0 . 0 0 0}$ & Valid \\
\hline X22 & $\mathbf{0 . 6 2 2}$ & $\mathbf{0 . 2 7 5}$ & $\mathbf{0 . 0 0 2}$ & valid \\
\hline X23 & $\mathbf{0 . 6 7 2}$ & $\mathbf{0 . 2 7 5}$ & $\mathbf{0 . 0 0 0}$ & Valid \\
\hline Y11 & $\mathbf{0 . 5 5 1}$ & $\mathbf{0 . 2 7 5}$ & $\mathbf{0 . 0 0 0}$ & valid \\
\hline Y12 & $\mathbf{0 . 6 4 5}$ & $\mathbf{0 . 2 7 5}$ & $\mathbf{0 . 0 0 0}$ & Valid \\
\hline Y13 & $\mathbf{0 . 8 0 8}$ & $\mathbf{0 . 2 7 5}$ & $\mathbf{0 . 0 0 0}$ & Valid \\
\hline Y14 & $\mathbf{0 . 6 9 9}$ & $\mathbf{0 . 2 7 5}$ & $\mathbf{0 . 0 0 0}$ & Valid \\
\hline
\end{tabular}

Berdasarkan tabel diatas, hasil pengelohan data tersebut menjelaskan bahwa semua indikator dalam tabel tersebut telah memiliki validitas yang dan signifikan dengan nilai correlation $>0.30$ dan signifikan $<0.50$.

Pengujian kedua yaitu uji Reliabilitas. Hasil pengujian sebagai berikut :

\section{Tabel 2. Uji Reliabilitas}

\begin{tabular}{|l|l|l|l|}
\hline Variabel & $\begin{array}{l}\text { Cronbach's } \\
\text { Alpha }\end{array}$ & $\begin{array}{l}\text { Batas } \\
\text { Minimal } \\
\text { Cronbach's } \\
\text { Alpha }\end{array}$ & Keterangan \\
\hline X1 & 0.827 & 0.60 & Reliabel \\
\hline X2 & 0.620 & 0.60 & Reliabel \\
\hline Y & 0.795 & 0.60 & Reliabel \\
\hline
\end{tabular}


Penelitian ini menggunakan 3 variabel yaitu Pelatihan (X1), Pengalaman (X2) dan Profesionalisme (Y). dalam penelitian dapat dijelaskan bahwa variavel pelatihan (X1) memiliki nilai Cronbach Alpha sebesar $0.827>0.60$, variabel pengalaman (X2) memiliki nilai Cronbach Alpha sebesar $0.620>0.60$, dan variabel profesionalisme pegawai (Y) memiliki nilai Cronbach Alpha sebesar 0.795>0.60. dapat disimpulkan bahwa untuk nilai Cronbach Alpha dari ketiga variabel tersebut memiliki nilai $>0.60$ sehingga seluruh variabel dalam penelitian ini lolos dalam uji reliabilitas dan dinyatakan reliabel Pengujian ketiga yaitu uji normalitas, dengan uji statistik nonparametrik Kolmogorovsmirnov(K-S). hasil pengujian ini adalah sebagai berikut :

Tabel 3. Uji normalitas

\begin{tabular}{|l|l|l|}
\hline \multicolumn{2}{|l|}{ One-Sample Kolmogorov-Smirnov Test } \\
\hline \multicolumn{2}{|l|}{} & $\begin{array}{l}\text { Unstandardized } \\
\text { Predicted Value }\end{array}$ \\
\hline $\mathrm{N}$ & Mean & 51 \\
\hline $\begin{array}{l}\text { Normal } \\
\text { Parameters }\end{array}$ & $\begin{array}{l}\text { Stb } \\
\text { Deviation }\end{array}$ & .36785773 \\
\hline $\begin{array}{l}\text { Most Extreme } \\
\text { Differences }\end{array}$ & Absolute & .107 \\
\cline { 2 - 3 } & Positive & .107 \\
\cline { 2 - 3 } & Negative & -.084 \\
\hline Test Statistic & .107 \\
\hline Asymp. Sig. (2-tailed) & $.200^{c, d}$ \\
\hline a. Test distribution is Normal. \\
\hline b. Calculated from data. \\
\hline c. Lilliefors Significance Correction. \\
\hline d. This is a lower bound of the true significance. \\
\hline
\end{tabular}

Berdasarkan tabel diatas, nilai asymp, sig (2talled) yaitu 0.200. nilai ini leibh besar dari 0.05 , apabila dibandingkan dengan nilai kriteria yang ada, dan disimpulkan bahwa dalam penelitian terdistribusi normal.

Pengjuian keempat, yaitu uji autokorelasi melaui Durbin Watson. Hasil pengujian sebagai berikut :
Tabel 4.Uji autokorelasi

\begin{tabular}{|l|l|l|l|l|l|}
\hline \multicolumn{5}{|c|}{ Model Summary } \\
\hline $\begin{array}{l}\mathrm{M} \\
\text { od } \\
\mathrm{el}\end{array}$ & $\mathrm{R}$ & $\begin{array}{l}\mathrm{R} \\
\text { Squar } \\
\mathrm{e}\end{array}$ & $\begin{array}{l}\text { Adjusted } \\
\text { R Square }\end{array}$ & $\begin{array}{l}\text { Std. Error } \\
\text { of the } \\
\text { Estimate }\end{array}$ & $\begin{array}{l}\text { Durbin- } \\
\text { Watson }\end{array}$ \\
\hline 1 & $.651^{\mathrm{a}}$ & .424 & .400 & .43784 & 2.042 \\
\hline
\end{tabular}

a. Predictors: (Constant), Moderasi, pelatihan

b. Dependent Variable: profesionalisme

Berdasarkan tabel diatas, nilai DW yaitu 2.042. sehingga, apabila nilai tersebut diamsukkan kedalam kriteria DW, diperoleh perbandingan sebagai berikut.

$$
\mathrm{DW}>\mathrm{dU} \rightarrow 2.042>1.675
$$

Kesimpulan dari pengujian autokorelasi dengan pengukuran Durbin-Watson yaitu tidak terdapat autokorelasi positif.

Pengujian kelima, yaitu uji multikolonearitas melalui tolarance dan Variance Inflation Factor (VIF). Hasil pengujian sebagai berikut.

Tabel 6. Uji heterokedastisitas

Tabel diatas menunjukkan nilai sig. pada

\begin{tabular}{|c|c|c|c|c|c|c|}
\hline \multicolumn{7}{|c|}{ Coefficients $^{\mathrm{a}}$} \\
\hline \multirow{2}{*}{\multicolumn{2}{|c|}{ Model }} & \multicolumn{2}{|c|}{$\begin{array}{l}\text { Unstandardized } \\
\text { Coefficients }\end{array}$} & \multirow{2}{*}{$\begin{array}{l}\text { Standardized } \\
\text { Coefficients } \\
\text { Beta }\end{array}$} & \multirow[t]{2}{*}{$\mathrm{T}$} & \multirow[t]{2}{*}{ Sig. } \\
\hline & & B & $\begin{array}{l}\text { Std. } \\
\text { Error }\end{array}$ & & & \\
\hline \multirow[t]{3}{*}{1} & (Constant) & .479 & .579 & & .828 & .412 \\
\hline & pelatihan & .637 & .162 & .564 & 3.942 & .000 \\
\hline & Moderasi & .037 & .043 & .124 & .864 & .392 \\
\hline \multicolumn{7}{|c|}{ a. Dependent Variable: profesionalisme } \\
\hline & $\begin{array}{l}\text { variabel } \mathrm{l} \\
\text { kecil } \\
\text { hetereroke } \\
\text { dengan } \mathrm{n} \\
\text { besar dar } \\
\text { heteroked } \\
\text { Pengujian } \\
\left(\mathrm{R}^{2}\right) \text { dan } \\
\text { determina } \\
\text { model reg } \\
\text { hasil uji se }\end{array}$ & $\begin{array}{l}\text { atiha } \\
\text { ri } \\
\text { stisi } \\
\text { i sg } \\
0.05 \\
\text { isita } \\
\text { etuju } \\
\text { rbag } \\
\left(\mathrm{R}^{2}\right) \\
\text { i se } \\
\text { gai }\end{array}$ & $\begin{array}{l}\text { (X1) } \\
0.05 \\
\text { dan } \\
\text { fikan } \\
\text { artiny } \\
\text { Jaitu } \\
\text { menja } \\
\text { ang p } \\
\text { rhana } \\
\text { ikut }\end{array}$ & $\begin{array}{l}\text { ebesar } 0.0 \\
\text { artinya } \\
\text { riabel mode } \\
\text { ebesar } 0.3 \\
\text { tidak me } \\
\text { efisien det } \\
2 \text {. uji } \\
\text { tama terkai } \\
\text { intuk H1, }\end{array}$ & $\begin{array}{l}\text { lebih } \\
\text { terjadi } \\
\text { asi }(\mathrm{M}) \\
\text { galami lebih } \\
\text { galamiansi } \\
\text { efisein } \\
\text { dengan } \\
\text { dengan }\end{array}$ & \\
\hline
\end{tabular}


Tabel 7.Uji koefisien determinasi $\left(\mathbf{R}^{2}\right)$

\begin{tabular}{|l|l|l|l|l|}
\hline \multicolumn{3}{|l|}{ Model Summary } \\
\hline $\begin{array}{l}\text { Mo } \\
\text { del }\end{array}$ & $\mathrm{R}$ & $\begin{array}{l}\text { R } \\
\text { Square }\end{array}$ & $\begin{array}{l}\text { Adjusted R } \\
\text { Square }\end{array}$ & $\begin{array}{l}\text { Std. Error of } \\
\text { the Estimate }\end{array}$ \\
\hline 1 & $.644^{\mathrm{a}}$ & .415 & .403 & .43670 \\
\hline a. Predictors: (Constant), pelatihan & \\
\hline
\end{tabular}

Tabel diatas menunjukkan nilai adjusted $R$ Square $\left(\mathrm{R}^{2}\right)$ sebesar 0.403 , yang artinya pelatihan kerja dapat menjelaskan profesionalisme pegawai sebesar $40.3 \%$

Uji koefesien determinasi $\left(\mathrm{R}^{2}\right)$ yang kedua terkait dengan model regresi moderasi untuk $\mathrm{H} 2$, dengan hasil sebagai berikut :

Tabel 8. Uji koefisien determinasi $\left(\mathbf{R}^{2}\right)$ Model Summary

\begin{tabular}{|l|l|l|l|l|}
\hline Model & $\mathrm{R}$ & $\begin{array}{l}\mathrm{R} \\
\text { Square }\end{array}$ & $\begin{array}{l}\text { Adjusted } \\
\text { R Square }\end{array}$ & $\begin{array}{l}\text { Std. Error } \\
\text { of the } \\
\text { Estimate }\end{array}$ \\
\hline 1 & $.487^{\mathrm{a}}$ & .237 & .222 & .49859 \\
\hline \multicolumn{3}{|c|}{ a. Predictors: (Constant), Moderasi } \\
\hline
\end{tabular}

Tabel diatas menunjukkan nilai adjusted $R$ Square $\left(\mathrm{R}^{2}\right)$ sebesar 0.222 , yang artinya variabel moderasi dapat menjelaskan profesionalisme pegawai semakin baik dengan adanya interaksi dari pelatihan dan pengalaman . hai ini dibuktikan dengan nilai adjusted $R$ Square $\left(\mathrm{R}^{2}\right)$ sebesar $22.2 \%$.

Pengujian kedelepan yaitu dengan uji Moderate Regression Analysis (MRA), dengan hasil sebagai berikut :

\section{$P=0.479 X 1+0.637 M+0.037 X 1 * M+e$}

Pengujian kesembilan yaitu uji kelayakan mode (uji F), dengan kriteria apabila nilai sig.< 0.05 maka Ha diterima. Hasil uji $\mathrm{F}$ sebagai berikut :
Tabel 9. Uji F

\begin{tabular}{|c|c|c|c|c|c|c|}
\hline \multicolumn{7}{|c|}{ ANOVA $^{\mathrm{a}}$} \\
\hline \multicolumn{2}{|c|}{ Model } & $\begin{array}{l}\text { Sum } \\
\text { of } \\
\text { Squar } \\
\text { es }\end{array}$ & $\begin{array}{l}\mathrm{d} \\
\mathrm{f}\end{array}$ & $\begin{array}{l}\text { Mea } \\
\mathrm{n} \\
\text { Squa } \\
\text { re }\end{array}$ & $\mathrm{F}$ & $\begin{array}{l}\text { Sig } \\
\text {. }\end{array}$ \\
\hline \multirow[t]{3}{*}{1} & $\begin{array}{l}\text { Regressi } \\
\text { on }\end{array}$ & 6.766 & 2 & $\begin{array}{l}3.38 \\
3\end{array}$ & $\begin{array}{l}17.6 \\
47\end{array}$ & $\begin{array}{l}.00 \\
0^{b}\end{array}$ \\
\hline & Residual & 9.202 & $\begin{array}{l}4 \\
8\end{array}$ & .192 & & \\
\hline & Total & $\begin{array}{l}15.96 \\
8\end{array}$ & $\begin{array}{l}5 \\
0\end{array}$ & & & \\
\hline \multicolumn{7}{|c|}{ a. Dependent Variable: profesionalisme } \\
\hline \multicolumn{7}{|c|}{ b. Predictors: (Constant), Moderasi, pelatihan } \\
\hline
\end{tabular}

Tabel diatas menunjukkan nilai sig sebesar 0.000, dan apabila dimasukkan kedalam kriteria yang ada . nlai sig. tersebut lebih kecil dari 0.05. yang artinya Ha diterima. Variabel Independen yang ada dalam penelitian secara stilmultan mempengaruhi profesionalisme pegawai.

Pengujian kesepuluh yaitu uji koefisien regresi parsial (uji T) dengan kriteria apabila nilai sig. $<0.05$ maka Ha diterima. Hasil uji T pertama untuk Ha1 yaitu :

Tabel 10. Uji T

\begin{tabular}{|c|c|c|c|c|c|c|}
\hline \multicolumn{7}{|c|}{ Coefficients $^{\mathrm{a}}$} \\
\hline \multirow{2}{*}{\multicolumn{2}{|c|}{ Model }} & \multicolumn{2}{|c|}{$\begin{array}{l}\text { Unstandardized } \\
\text { Coefficients }\end{array}$} & $\begin{array}{l}\text { Standa } \\
\text { rdized }\end{array}$ & \multirow[t]{2}{*}{$\mathrm{t}$} & \multirow[t]{2}{*}{ Sig } \\
\hline & & B & $\begin{array}{l}\text { Std. } \\
\text { Error }\end{array}$ & Beta & & \\
\hline \multirow[t]{2}{*}{1} & $\begin{array}{l}\text { (Co } \\
\text { nsta } \\
\text { nt) }\end{array}$ & 1.016 & .640 & & $\begin{array}{l}1.5 \\
86\end{array}$ & $\begin{array}{l}.11 \\
9\end{array}$ \\
\hline & $\begin{array}{l}\text { Mod } \\
\text { erasi }\end{array}$ & .145 & .037 & .487 & $\begin{array}{l}3.9 \\
03\end{array}$ & $\begin{array}{l}.00 \\
0\end{array}$ \\
\hline
\end{tabular}

Tabel diatas menunjukkan nilai sig. sebesar 0.000 , maka ha diterima atau pelatihan kerja berpengaruh terhadap profesionalisme pegawai. Hasil ini sesuai pula terhadap penelitian sebelumnya yang dilakukan oleh Ronal Aprianto (2015).

hasil uji T kedua untuk Ha2 yaitu : 
Tabel 11. Uji T

\begin{tabular}{|c|c|c|c|c|c|c|}
\hline \multicolumn{7}{|c|}{ Coefficients $^{\mathrm{a}}$} \\
\hline \multirow{2}{*}{\multicolumn{2}{|c|}{ Model }} & \multicolumn{2}{|c|}{$\begin{array}{l}\text { Unstandardized } \\
\text { Coefficients }\end{array}$} & \multirow{2}{*}{$\begin{array}{l}\text { Standardized } \\
\text { Coefficients } \\
\text { Beta }\end{array}$} & \multirow[t]{2}{*}{$\mathrm{T}$} & \multirow[t]{2}{*}{ Sig. } \\
\hline & & B & $\begin{array}{l}\text { Std. } \\
\text { Error }\end{array}$ & & & \\
\hline \multirow[t]{2}{*}{1} & (Constant) & .773 & .467 & & 1.656 & .104 \\
\hline & pelatihan & .727 & .123 & .644 & 5.893 & .000 \\
\hline \multicolumn{7}{|c|}{$\begin{array}{l}\text { a. Dependent Variable } \\
\text { : profesionalisme }\end{array}$} \\
\hline
\end{tabular}

Manusia” Perusahaan Bandung : Rosda

Dwiyanto, dkk, 2011 "Mengembalikan kepercayaan publik Melalui Reformasi Birokrasi, Penerbit : PT Gramedia Pustala Utama, Jakarta Drs. H. Melay, S.P Hasibuan, 2007. "manajemen Sumber Daya Manusia" Jakarta : Cetakan 9. PT. Bumi Aksara

Foster, 2001. "Pembinaan Untuk Peningkatan Kinerja Karyawan" PPM : Jakarta.

Berdasarkan tabel diatas dengan nilai sig. yang telah diketahui, dapat disimpulkan bahwa pegalaman kerja sebaai variabel moderasi mampu memoderasi pengaruh pelatihan kerja terhadap profesionalisme pegawai

Hasil penelitian ini sejalan dengan penelitian Ronal Aprianto SE, M.Si (2015) Pengaruh Pelatihan dan Pengalaman Kerja terhadap Profesionalisme Pegawai Pada Kantor Lapas Narkotika Kelas IIA Lubuklinggu. yang menyatakan bahwa pelatihan kerja secara parsial berpengaruh positif dan signifikan terhadap profesionalisme

\section{KESIMPULAN DAN SARAN}

Pelatihan kerja bepengaruh signifikan terhadap profesionalisme pegawai dan pengalaman kerja sebagai variabel moderasi memperkuat hubungan pelatihan kerja terhadap profesionalisme pegawai. dari hasil analisis dan pembahasan yang telah diuraikan sebelumnya maka penulis menarik kesimpulan atas hasil analisis berdasarkan uji $\mathrm{T}$, uji F dan uji Moderatet Regression Analysis (MRA) menunjukan terdapat pengaruh efek moderasi antara hubungan pelatihan kerja terhadap profesionalisme pegawai.

\section{REFERENSI}

Affandi, M. Joko, "Netralitas dan Profesionalitas Pegawai Negeri Sipil, dalam Wacana Pengembangan Kepegawaian" Badan Kepegawaian Negara. Jakarta.

A.A Anwar Peabu Mangkunegara. 2011 "Manajemen Sumber Saya
Hasibuan, 2010. "Manajemen Sumber Daya Manusia”. PT Bumi Aksra. Jakarta.

H. Simamora. 2010. "Manajemen Sumber Daya Manusia”. Yogyakarta : STIE YKNPN.

Hasibuan Melayu S,P. 2016 "Manajemen Sumber Daya Manusia”. Edisi Revisi. Jakarta. Penerbit PT. Bumi Aksara

Keraf, sonny.1998 "Etika Bisnis, Tuntutan dan Relevansinya". Edisi Baru. Jakarta: Penerbit Kanisius

Mangkunegara, Anwar Prabu. A.A, 2013. "Manajemen Sumber Daya Manusia Perusahaan". Penerbit : Remaja Rosda karya. Bandung

Suryana. 2011. "Kewirausahaan". Jakarta : Salemba Empat.

Tadampali, dkk, 2016. "Pengaruh Iklim Oraganisasi terahadap turnover sebagai variabel Interving Pada PT. Bank SULSELBAR, Universitas Negeri Malang Makassar, Jurnal Adminstrasi Publik, Vol 6 No,2

Widodo, 2012. "Manajemen Pengembangan Sumber Daya Manusia". Penerbit : Pustaka Pelajar, Yogyakarta.

Zuhro,R. S. 2016. "Good Governace dan Reformasi Biokrasi di Indonesia". Jurnal Penelitian Politik Intention Melalui Kepuasaan Kerja 